\begin{tabular}{|l|l|}
\hline Title: & $\begin{array}{l}\text { An analysis of the shear-transfer actions in reinforced concrete members without } \\
\text { transverse reinforcement based on refined experimental measurements }\end{array}$ \\
\hline Authors: & Cavagnis F., Fernández Ruiz M., Muttoni A. \\
\hline Published in: & Structural concrete \\
\hline Pages: & pp. $1-16$ \\
\hline Year of publication: & 2017 \\
\hline Type of publication: & Peer reviewed journal article \\
\hline
\end{tabular}

Please quote as:

Cavagnis F., Fernández Ruiz M., Muttoni A., An analysis of the shear-transfer actions in reinforced concrete members without transverse reinforcement based on refined experimental measurements, Structural concrete, 2017, pp. 1-16. 


\title{
An analysis of the shear-transfer actions in reinforced concrete members without transverse reinforcement based on refined experimental measurements
}

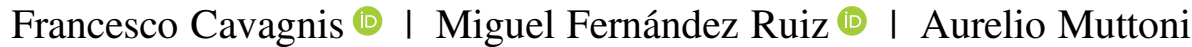

École Polytechnique Fédérale de Lausanne,

School of Architecture Civil and Environmental

Engineering, Lausanne, Switzerland

Correspondence

Francesco Cavagnis, École Polytechnique

Fédérale de Lausanne, School of Architecture

Civil and Environmental Engineering, Station

18, CH-1015, Lausanne, Switzerland.

Email: francesco.cavagnis@epfl.ch

Funding information

Bundesamt für Strassen, Grant/Award number: AGB-2011-015
A traditional difficulty in the understanding of the role of the various sheartransfer actions in members without transverse reinforcement has been a lack of detailed measurements on the development of shear cracking and their associated kinematics during the process of failure. In this paper, this issue is addressed on the basis of an experimental program on 20 beams investigated by means of digital image correlation. The measurements are shown to allow a clear understanding of the mechanisms leading to shear failure and their evolution (transfer of forces between the various potential shear-carrying actions) during the loading process. The amount of shear carried by the various potential shear-transfer actions is estimated for varying levels of load accounting for the cracking pattern and actual kinematics on the basis of fundamental constitutive laws for concrete and steel. The results are shown to be consistent and provide a rational basis for the understanding of the phenomenon of shear transfer in reinforced concrete members without transverse reinforcement.

\section{KEYWORDS}

digital image correlation (DIC), experimental program, mechanisms of shear failure, shear, shear-transfer actions

\section{1 | INTRODUCTION}

Shear design of one-way slabs and beams without shear reinforcement has attracted significant research efforts in the last decades. These studies have allowed recognizing the different shear-transfer actions that contribute to the shear strength of reinforced concrete members without transverse reinforcement. ${ }^{1,2}$ Traditionally, the shear-transfer actions are classified $^{3}$ into beam shear-transfer actions (where the force in the tension chord varies and transverse tensile stresses develops) and the arching action (where the force in the tension chord is constant and no transverse tensile stresses are necessary for carrying shear). With respect to the beam

Discussion on this paper must be submitted within two months of the print publication. The discussion will then be published in print, along with the authors' closure, if any, approximately nine months after the print publication. shear-transfer actions, ${ }^{3}$ shear can be carried by the so-called cantilever action, ${ }^{4}$ the residual tensile strength, the dowelling action, or the aggregate interlock.

Various approaches for shear design have been developed in the past considering one of these actions as governing (compression zone ${ }^{5-7}$ aggregate interlock ${ }^{8}$ ) or combining them. ${ }^{9-12}$

Despite these research efforts, there is still no general consensus on the main parameters governing the shear resistance and the mechanisms triggering the shear failure. In this context, detailed measurements of the failure process are probably the most consistent manner to advance on this issue. With this respect, digital image correlation (DIC) is a very suitable tool that allows tracking the displacement field and investigating the redistribution between the different load-carrying actions and the process of failure. ${ }^{13}$ 
In this paper, the results of seven beams are presented, completing a previous experimental campaign on 13 beams without transverse reinforcement reproducing various loading and support conditions. ${ }^{13}$ Detailed DIC measurements were recorded and used to track the crack shape and kinematics. On that basis, a complete analysis of the various potential sheartransfer actions is performed during loading as well as in the instants before and after reaching the maximum load. This analysis is performed by accounting for the measured kinematics and by using fundamental mechanical models. As a result, this paper aims at clarifying the role of the sheartransfer actions in the failure process and to identify the mechanisms triggering the shear failure.

\section{2 | EXPERIMENTAL PROGRAM}

In Cavagnis et al, ${ }^{13} 17$ tests on 13 beams without shear reinforcement (SC51-SC57, SC59, SC61-SC65), tested under different loading conditions were presented. That experimental program is completed in this manuscript with eight additional tests on seven beams (SC58, SC60, SC66-SC70, refer to Table 1). The test setup was maintained (a detail description of the test setup is provided by Cavagnis et $\mathrm{al}^{13}$ ) allowing to reproduce various loading and support conditions (Figure 1): simply supported beams (Figure 1b), continuous beams (Figure 1c), and cantilevers (Figure 1d) subjected to distributed loading and cantilevers subjected to point loading, where the load is concentrated at the end of the cantilever (acting on a distance of $700 \mathrm{~mm}$, Figure 1e).

The investigated specimens had a rectangular cross section of $250 \times 600 \mathrm{~mm} .{ }^{13}$ Two amounts of longitudinal reinforcement ratio were used: $\rho=0.54 \%$ (corresponding to two bars diameter $22 \mathrm{~mm}$, effective depth $d=559 \mathrm{~mm}$ ) and $\rho=0.89 \%$ (corresponding to two bars diameter $28 \mathrm{~mm}$, effective depth $d=556 \mathrm{~mm}$ ). The top and bottom reinforcement were identical.

All beams were cast with normal-strength concrete with maximum aggregate size $d_{g}$ of $16 \mathrm{~mm}$. At the time of testing, the measured cylinder compressive strength $f_{c}$ varied between 31.2 and $36.9 \mathrm{MPa}$. Tensile reinforcement consisted in high-strength deformed steel bars with average yield stress of $713 \mathrm{MPa}$ (bar diameter $28 \mathrm{~mm}$ ) and $760 \mathrm{MPa}$ (bar diameter $22 \mathrm{~mm}$ ). The average ultimate tensile strength after strain hardening was $820 \mathrm{MPa}$ (bar diameter $28 \mathrm{~mm}$ ) and $920 \mathrm{MPa}$ (bar diameter $22 \mathrm{~mm}$ ).

The test setup allowed varying the loading conditions and the shear slenderness. All details concerning the

TABLE 1 Geometrical and material properties of the tested specimens and failure loads ( $V_{\text {left: }}$ shear force at the end [left] support; $V_{\text {right }}$ shear force at the intermediate (right) support; $M /(V d)$ refers to internal forces at the right support; CCDT refers to the Critical Crack Development Type)

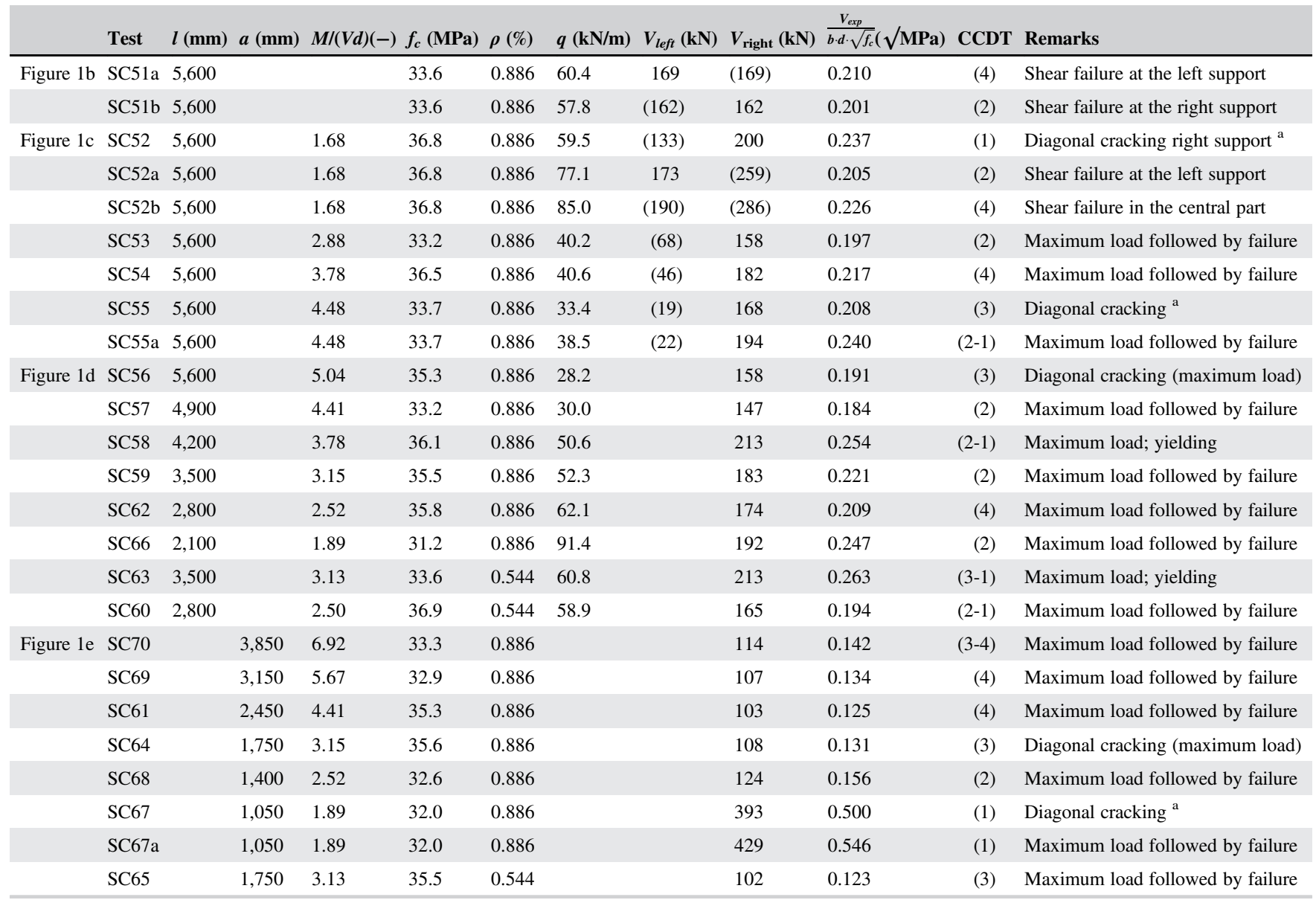

${ }^{\text {a }}$ Diagonal cracking followed by a drop in the applied load of 5-10\%; the specimen could be reloaded to larger shear strengths. 


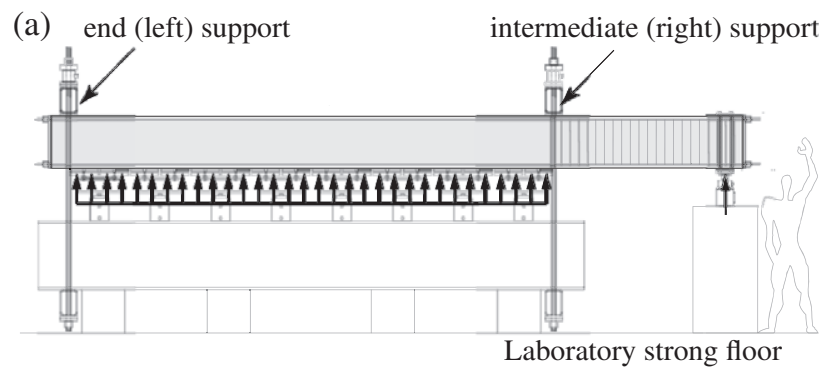

(b)

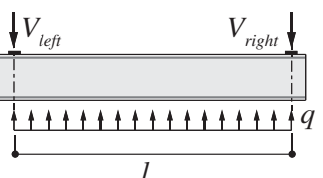

(c)

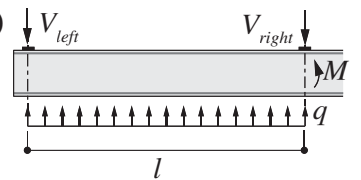

(d)

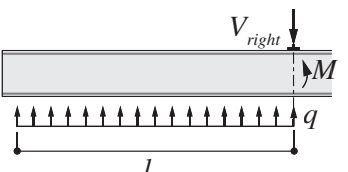

(e)

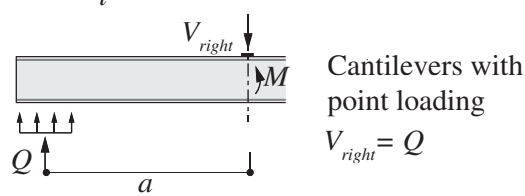

FIGURE 1 Experimental program: (a) scheme of the test setup and loading conditions: (b) simply supported beams, (c) continuous beams and (d) cantilevers subjected to uniformly distributed loading, (e) cantilevers subjected to point loading (for more detailed description of the test setup, see Cavagnis et al. ${ }^{13}$ )

properties of the specimens (material properties, geometry, and test results) are summarized in Table 1. All beams failed in shear (in tests SC58, SC63 and SC67a after yielding of the flexural reinforcement) and presented different cracking patterns at failure (refer to Figure 2). In particular, specimen SC67 developed a diagonal crack close to the right support, leading to a drop in the applied load (about $8 \%)$. The specimen however could be reloaded and failure occurred due to concrete crushing (SC67a in Table 1).

\section{1 | Measurement of the crack kinematics}

In addition to conventional measurement techniques, threedimensional DIC has been used to track the cracking pattern and the displacement field of the specimens. The DIC required painting the surface of the specimens with a speckle pattern. Photogrammetry was performed on the entire surface of the beams with two digital cameras Nikon D800, Nikon Corporation, Japan (36.3 megapixels). The pattern applied to the entire surface consisted of rounded speckles of constant size and not overlapping. Speckles varied between 1 and $2 \mathrm{~mm}$ as a function of the size of the investigated specimen, and the dimension of each pixel was approximately $0.35 \mathrm{~mm}$ (with an upper value of $0.6 \mathrm{~mm}$ for the large specimens). In addition, two cameras Manta, Allied Vision Technologies, Germany (5 Megapixels) were installed on the opposite side of the beam in order to monitor the compression zone close to the intermediate support (right support in Figure 1). In this area, the pattern was sprayed uniformly on the surface and the images had a resolution of $0.2 \mathrm{~mm} / \mathrm{pixel}$. The image acquisition rate of the cameras varied during the test and was increased up to $1 \mathrm{~Hz}$ (in some tests up to $2 \mathrm{~Hz}$ ) prior to failure.

The main challenge of using the DIC technique was to obtain a good accuracy in measuring displacements and strains. Images were analyzed using the VIC3D software. ${ }^{14}$ Each image was divided into a grid of facets which were used to track the displacements between images. Within the facets, displacements were computed at specific points, with a maximum error of $1 / 50$ of a pixel. Strains were computed directly from the measured displacement points. Principal strains have been observed to be influenced by the dimension of the area used for the calculation. In this paper, the value of the strains in the compression zone have been computed from the images taken by the cameras Manta, assuming an area of approximately $50 \times 50 \mathrm{~mm}$, which was reduced if the thickness of the compression zone was smaller than the assumed area.

\section{2 | Main results}

The measured shear strengths are presented in Table 1 and Figure 3. With respect to the influence of the shear slenderness ratio $a / d$ on the shear strength of cantilevers subjected to concentrated load, it can be observed that the shear stress at failure was significantly larger for specimen SC67 $(a / d<2.5)$ than for the other specimens $(a / d>2.5)$ (Figure 3a). The development of the critical crack (refer to Figure 2) and its influence on the shear strength of the member shows a strong dependency on the shear slenderness ratio, as already noted by Kani. ${ }^{4}$ For specimen SC67, the critical crack did not develop through the theoretical inclined compression strut and thus the flexural strength could almost be reached. For specimens with larger values of $a / d$, the critical cracks developed through the theoretical compression strut between loading and support, ${ }^{3}$ decreasing consequently the shear strength. For specimen SC70 $(a / d \approx 7)$, the flexural strength could again be reached (Figure 3b).

The influence of the shear slenderness can also be observed for cantilevers subjected to distributed loading (refer to Figure 3c): the shear strength at the intermediate support decreases for increasing value of the length-to-span ratio $(l / d)$.

The effect of the location of the point of contraflexure in continuous beams (due to the different acting moment at the intermediate support, $M_{\text {right }}$ ) is depicted in Figure 3d. It can be observed that in general this parameter does not appear to have a notable influence on the shear strength at the intermediate support $\left(V_{\text {right }}\right)$. 


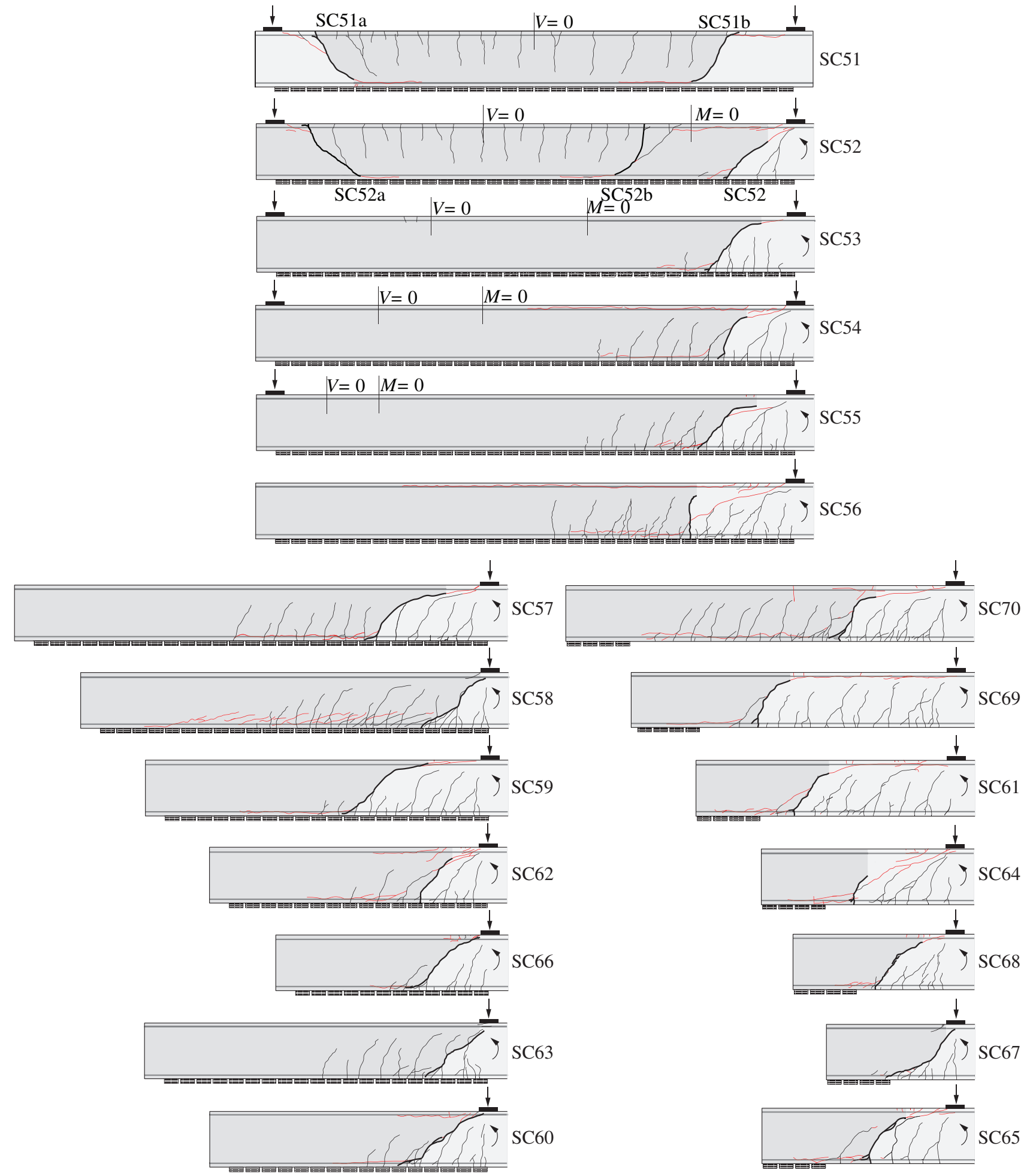

FIGURE 2 Observed cracking patterns and considered rigid bodies for the calculation of the shear-transfer actions (cracks in black for increasing load until maximum load, cracks in red after maximum load)

With respect to the influence of the direct strut action of the distributed loads near supports, it was recently investigated by Pérez Caldentey et al, ${ }^{15}$ who showed that the loads applied near the support do not need to be transferred through the critical shear crack, but can directly be strutted to the support. In Reference 15, it was concluded that these direct struts justify the increase on the shear force observed for members subjected to distributed loading compared to members subjected to point loading. The tests presented in this manuscript and in Reference 13 confirm that for slender members, the shear resistance effectively increases when uniformly distributed load is applied (refer to Table 2). For non-slender members, however, this influence depends on the location and shape of the critical shear crack. For instance, within the present testing program, for specimen SC66 (distributed load) developing the full-arching action 
(a)

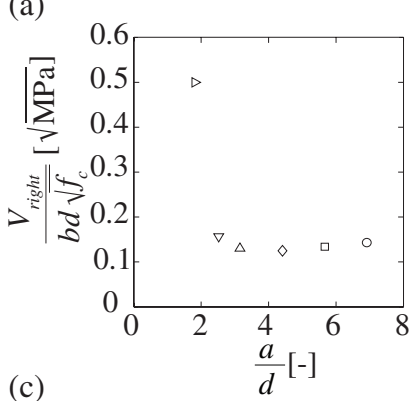

(b)

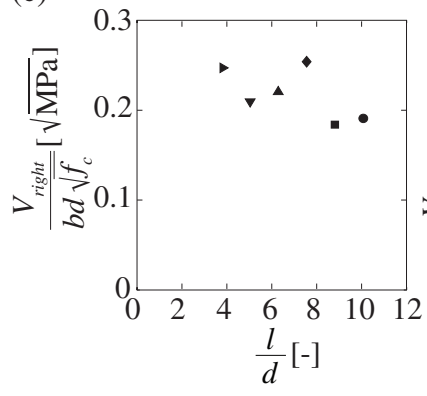

(d)
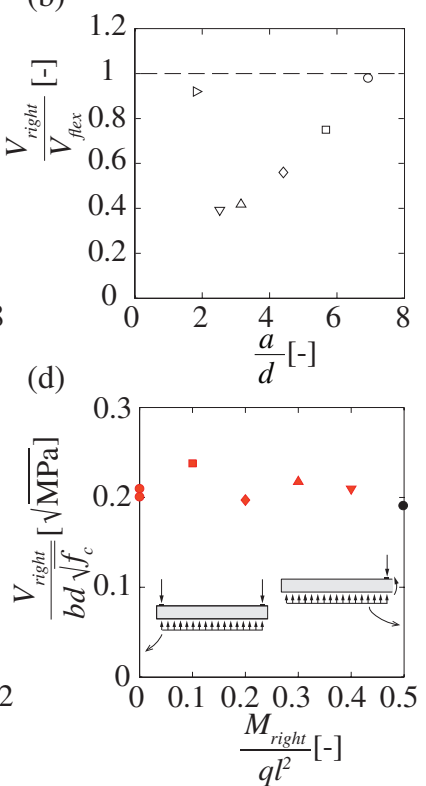

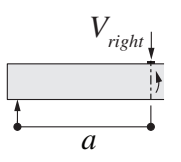

- $\mathrm{SC70}$

口 SC69

$\diamond \mathrm{SC61}$

$\triangle$ SC64

$\nabla \mathrm{SC} 68$

$\triangleright$ SC67

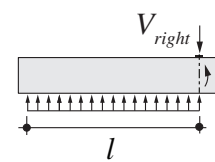

- $\mathrm{SC56}$

- SC57

- SC58

- SC59

$\checkmark$ SC62

- SC66

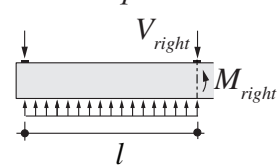

- SC51a,SC51b

- SC52

$\checkmark$ SC53

$\triangle \mathrm{SC} 54$

$\nabla$ SC55
FIGURE 3 (a) Influence of the shear slenderness ratio $(a / d)$ on the shear strength of cantilevers subjected to point loading; (b) comparisons of the experimental results with the flexural strength for cantilevers subjected to point loading; (c) influence of the shear slenderness on the shear strength of cantilevers subjected to distributed loading; (d) influence of the moment at the intermediate support on the shear strength for continuous beams subjected to distributed loading (only tests with $\rho=0.89 \%$ are considered)

was not possible since the theoretical direct compression strut was intercepted by the critical crack, whereas for specimen SC67 (point load) the critical crack did not penetrate within the theoretical strut ${ }^{3}$ and the plastic strength could almost be reached.

\section{3 | CRACKING PATTERN}

\section{1 | Critical shear crack and failure crack}

By means of the DIC technique, the cracking pattern could be tracked in a very detailed manner. A number of typical cracks has been identified and named, according to the notation presented by Cavagnis et al $^{13}$ (refer to Figure 4 for the definition of crack types). The critical shear crack will be referred to an existing crack (type A-F or type A-E, Figure $4 \mathrm{~b}$ ), whose development and opening lead to the failure of the specimen. The final failure surface, which develops after reaching the maximum load, may however not be completely coincident with the critical shear crack and will be named hereafter as the failure crack. ${ }^{13}$

Four different developments of failure cracks have been previously identified (see Reference 13 and Figure 5) and are confirmed with the new experiments:

- Critical shear crack allowing full-arching action to develop (Critical Crack Development Type 1, CCDT 1). This crack development has been observed for specimens with crack propagating at locations such that a direct compression strut can develop without being disturbed by the development of the critical shear crack (Figure 5a, e.g., specimen SC67).

- Failures following a stable propagation of the critical shear crack (CCDT 2). This failure type is characterized by the development within the compression zone of a quasihorizontal crack (crack type F) from a primary flexural crack (crack type A) in a stable manner up to failure (crack A-F, Figure 5b, e.g., specimen SC68). A secondary flexural crack (crack type $\mathrm{C}$ ) can merge with a primary flexural crack at low load level followed by a stable development of a crack type F (Figure 5c, e.g., specimen SC57).

- Failure triggered by local loss of aggregate interlock capacity due to the propagation of an internal crack (CCDT 3). This failure type is determined by the development of a diagonal aggregate-interlock crack (crack type E') from a primary flexural crack, due to large aggregate-interlock forces, ${ }^{13}$ leading to failure of the specimen (Figure 5d, e.g., specimens SC56 and SC64).

- Failure triggered by the merging of a secondary flexural crack (crack type C) with a primary flexural crack (crack type A) (CCDT 4). This failure type has been observed to be due to the merging of a crack type $\mathrm{C}$ with a crack type A-F, leading to an increase of the opening of the critical shear crack and a loss of shear-carrying capacity, triggering failure (Figure 5e, e.g., specimens SC61 and SC69).

The observed critical crack development types (CCDTs) are given for every tests in Table 1. It is important to note that different failure modes may lead to similar shear capacity and that similar members may develop rather different failure cracks.

\section{4 | ANALYSIS OF THE SHEAR-TRANSFER ACTIONS}

A methodology to evaluate the amount of force carried by each shear-transfer action on the basis of the crack kinematics was presented by Campana et al. ${ }^{16}$ Similar calculations have been presented recently by Huber et $\mathrm{al}^{17}$ using a consistent approach confirming its validity. The results of these studies showed that the governing shear-transfer actions depend mainly on the kinematics and on the shape of the critical crack and may significantly vary even for similar 
TABLE 2 Shear force at failure at the right support for cantilevers subjected to point and distributed load, $M /(V d)$ refers to internal forces at the right support

\begin{tabular}{|c|c|c|c|c|}
\hline $\begin{array}{l}\text { Test with distributed load / } \\
\text { Test with point load }\end{array}$ & $\frac{\boldsymbol{M}}{\boldsymbol{V} \cdot \boldsymbol{d}}(-)$ & $\frac{\boldsymbol{V}_{\text {right, }, \text { distr. }}}{\boldsymbol{b} \cdot \boldsymbol{d} \cdot \sqrt{\boldsymbol{f}_{\boldsymbol{c}}}}(\sqrt{\mathrm{MPa}})$ & $\frac{V_{\text {right, point }}}{\boldsymbol{b} \cdot \boldsymbol{d} \cdot \sqrt{\boldsymbol{f}_{\boldsymbol{c}}}}(\sqrt{\mathrm{MPa}})$ & $\frac{\boldsymbol{v}_{\text {distr. }}}{\boldsymbol{v}_{\text {point }}}(-)$ \\
\hline SC57/SC61 & 4.41 & 0.184 & 0.125 & 1.48 \\
\hline SC59/SC64 & 3.15 & 0.221 & 0.131 & 1.69 \\
\hline SC63/SC65 & 3.13 & 0.263 & 0.123 & 2.14 \\
\hline SC62/SC68 & 2.52 & 0.209 & 0.156 & 1.34 \\
\hline SC66/SC67 & 1.89 & 0.247 & 0.500 & 0.49 \\
\hline
\end{tabular}

specimens. However, little information is available on the phenomena governing the shear strength during failure (in particular before and after reaching the peak load).

In the following, the investigation of the shear-transfer actions is performed by considering the cracks and rigid bodies highlighted in Figure 2. The forces potentially acting on them are illustrated in Figure 6. The total shear force at the right support can be considered equal to the sum of the vertical component of the shear-transfer actions that are transferred through the critical shear crack $\left(V_{A g g}\right.$ : aggregate interlock; $V_{R S}$ : residual tensile strength of concrete; $V_{D, t e n s}$ : dowelling action of the tensile reinforcement; $V_{D \text {,compr }}$ : dowelling action of the compression reinforcement, when the critical shear crack intercepts the compression reinforcement; $V_{C}$ : inclined compression chord or arching action) and, in the case of members subjected to distributed loading, the amount of load which is directly strutted to the support $V_{q}$ without crossing the critical shear crack (refer to Figure 6).

The amount of shear transferred by the various sheartransfer actions is estimated on the basis of the measured crack kinematics and by using different constitutive models, which are explained below. For the calculation of the sheartransfer actions, the shape of the crack is approximated by a polyline whose points are spaced at a maximal distance equal to $16 \mathrm{~mm}$. The crack kinematics is on that basis calculated using the DIC measurements, consistently with the approach presented and validated by Campana et al. ${ }^{16}$

\section{1 | Aggregate interlock contribution}

Aggregate interlock was early acknowledged as an important mode of transfer shear across cracks. ${ }^{1}$ This action develops through contact in the rough cracks, developing normal and tangential stresses and allowing thus to transfer shear forces. (a)

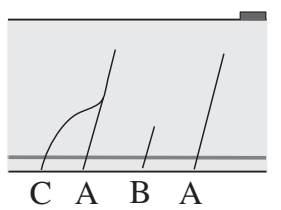

(b)

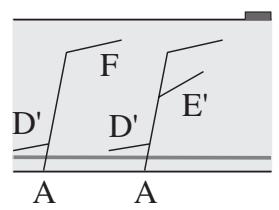

(c)

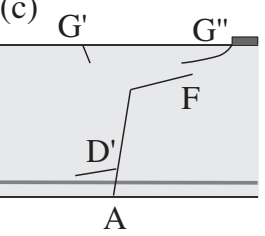

FIGURE 4 (a-c) Definition of crack types (refer to Cavagnis et $\mathrm{al}^{13}$ )
In the literature, several models have been proposed to calculate aggregate interlock stresses. ${ }^{18-20}$ In this paper, the two-phase model proposed by Walraven ${ }^{18}$ will be used due to its physical basis. The two-phase model is a mechanical approach based on statistical and geometrical considerations of the crack surfaces and the associated contact areas between the aggregate particles and the cement matrix. The model allows calculating the interface stresses by means of the following equations:

$$
\sigma=\sigma_{p u} \cdot\left(A_{x}-\mu \cdot A_{y}\right)
$$

and

$$
\tau=\sigma_{p u} \cdot\left(A_{y}+\mu \cdot A_{x}\right),
$$

where $\sigma_{p u}$ is the compressive plastic strength of the cement matrix, $\mu$ is a coefficient of friction and $A_{x}$ and $A_{y}$ are respectively the sum of the projections $a_{x}$ and $a_{y}$ of the contact surfaces between the aggregate particles and the cement matrix (see Figure 7a). The projections $a_{x}$ and $a_{y}$ are derived as a function of the crack opening $w$ and sliding $\delta$ and the maximum aggregate size $d_{g}$.

With respect to the crack kinematics, Walraven ${ }^{18}$ assumed that the crack opening $w$ develops completely prior to the crack sliding $\delta$ (refer to Figure $7 \mathrm{~b}$ ). Ulaga $^{21}$ applied the same model by using a different crack kinematics, assuming that the crack opening $w$ and the sliding $\delta$ develop simultaneously at a constant angle $\gamma$ (refer to Figure 7c). The main difference between the original kinematics and (a)

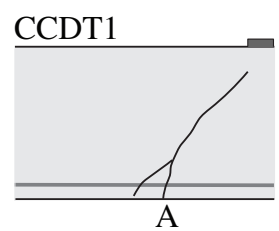

(d)

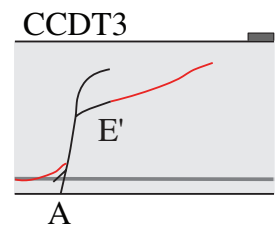

(b)

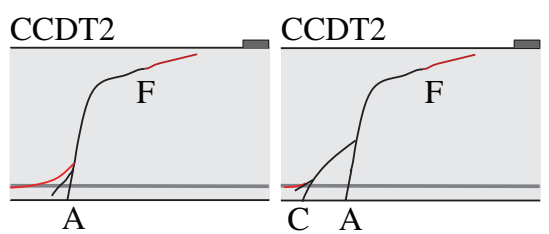

(e)

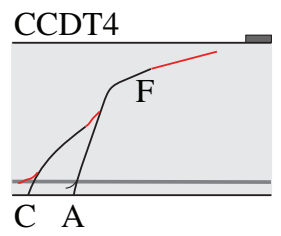

FIGURE 5 (a-e) Critical Shear Crack Development Types (CCDT, refer to Cavagnis et al, ${ }^{13}$ cracks in black for increasing load until maximum load, cracks in red after maximum load) 
(a)

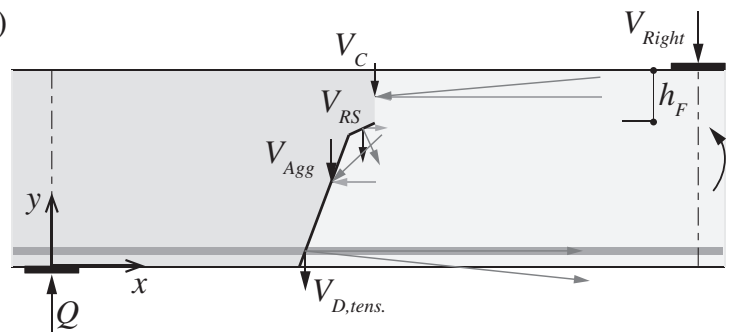

(b)

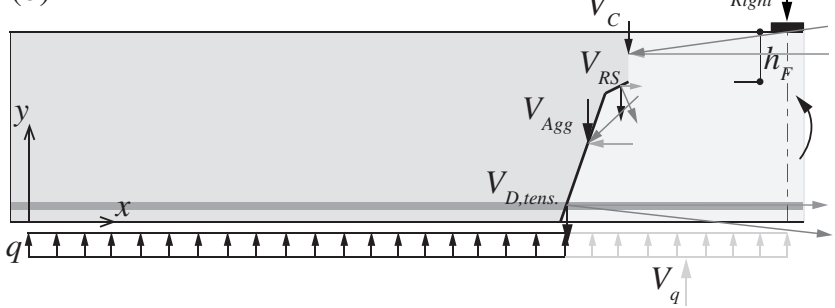

FIGURE 6 Analysis of shear-transfer actions: free-body equilibrium and internal forces: (a) cantilever subjected to point load; (b) cantilver subjected to distributed load

the one proposed by Ulaga can be identified in the different projections $a_{x}$ and $a_{y}$ of the contact surfaces between the aggregates and the cement matrix (Figure $7 \mathrm{~b}$ and Figure $7 \mathrm{c}$, respectively). A detailed analysis of the two-phase model and the calculated shear and normal stresses as a function of the different crack kinematics can be found elsewhere. ${ }^{13,16,23}$

In Figure $7 \mathrm{e}-\mathrm{f}$, the shear stresses measured by Jacobsen et $\mathrm{al}^{22}$ (black lines in the figure) for some double notch concrete specimens tested under different kinematics (first a mode I, where an initial crack opening $w_{O}$ is created between notches, followed by a mixed-mode kinematics, with combined opening and sliding at an angle $\gamma_{T}$, refer to Figure 7d) are compared to the shear stresses calculated according to the model of Walraven and using the crack kinematics proposed by Walraven (green lines) and Ulaga (red lines). It shall be noted that the crack kinematics imposed by Jacobsen et $\mathrm{al}^{22}$ is a representative of the kinematics experimentally measured in the upper and steeper parts of the critical shear crack of slender members, where the largest aggregate interlock stresses are activated (initial opening $w_{0}<0.05 \mathrm{~mm}$ and mixed-mode angle $\gamma>45^{\circ}$, refer to Reference 13).

In Figure $7 \mathrm{e}-\mathrm{f}$, it can be observed that the pre- and post-peak response is overestimated when the crack kinematics proposed by Walraven is adopted. On the contrary, the kinematics of Ulaga leads to solutions that slightly underestimate the peak stresses and overestimate the postpeak stresses for sliding larger than $0.25 \mathrm{~mm}$. On that basis, the transferred normal and shear interface stresses are estimated using the crack kinematics proposed by Ulaga, ${ }^{21}$ which better reproduces the kinematics experimentally measured in comparison to the one assumed by Walraven ${ }^{18}$ and provides a lower bound solution of the aggregate interlock stresses.
Finally, by integration of the stresses along the crack in the vertical direction, the shear force $V_{\text {Agg. }}$ is obtained (Figure 6).

\section{2 | Concrete residual strength contribution}

The residual tensile strength of concrete consists on the capacity to transfer tensile stresses through the fracture process zone of a crack. ${ }^{24}$ As experimentally observed, ${ }^{13}$ the top part of the critical shear crack (quasi-horizontal part) is characterized by a pure mode I opening response and is thus governed by the residual tensile strength of concrete. $^{9}$

In this paper, the relation proposed by Hordijk ${ }^{25}$ for the concrete residual strength is used (see Figure 8a):

$\sigma_{\text {res }}=f_{c t}\left[\left(1+\left(c_{1} \frac{w}{w_{c}}\right)^{3}\right) \mathrm{e}^{-c_{2}\left(w / w_{c}\right)}-\frac{w}{w_{c}}\left(1+c_{1}^{3}\right) \mathrm{e}^{-c_{2}}\right]$,

where $w_{c}=5.14 \cdot\left(G_{F} / f_{c t}\right)$ represents the maximum crack width for stress transfer, $c_{1}=3$ and $c_{2}=6.93$ are constants, $G_{F}$ is defined according to fib Model Code $2010^{26}$ equal to:

$$
G_{F}=73 \cdot f_{c}^{0.18}\left(\frac{\mathrm{N}}{\mathrm{m}}, \mathrm{MPa}\right)
$$

and the tensile strength of concrete $f_{c t}$ is assumed equal to $f_{c t}=0.3 \cdot f_{c}^{2 / 3}$ (for $f_{c}<50 \mathrm{MPa}^{26}$ ). Only openings $w$ larger than $0.02 \mathrm{~mm}$ (accounting for DIC reliability) have been considered for the calculation of the residual tensile stresses, as the position of the crack tip has been assumed where the relative displacements reach that value.

Due to the crack inclination, the normal stresses in the crack lead to a component in the vertical direction, named $V_{R S}$ (Figure 6).

\section{3 | Dowelling action}

The dowelling action refers to the capacity of flexural reinforcement bars to transfer shear forces across the crack, which can be activated when the longitudinal reinforcement follows a transversal displacement. In the analyses presented in this paper, the dowelling contribution of the tensile reinforcement $V_{D \text {,tens }}$ is obtained from the measured displacements of the concrete surface in the vicinity of the critical shear crack. It is assumed that the bar is unbonded in a length $l_{d a}=l_{d}+d_{b}$, where $l_{d}$ is the horizontal length affected by the dowelling crack and $d_{b}$ is the diameter of the bar. The deflection is approximated to a third-order polynomial on the basis of the vertical displacements and rotations at the extremities of $l_{d a}\left(v_{0}, v_{0}{ }^{\prime}\right.$, and $\left.v_{1}, v_{1}{ }^{\prime}\right)$, which are derived through the measurements of two points located in each external region at a distance $x_{d}=d_{b} / 2$ (refer to Figure 8b). Assuming a linear-elastic behavior of the bar and differentiating three times, the deflection with respect to $x$ coordinate, the shear carried by the dowelling action can be obtained: 
(a)

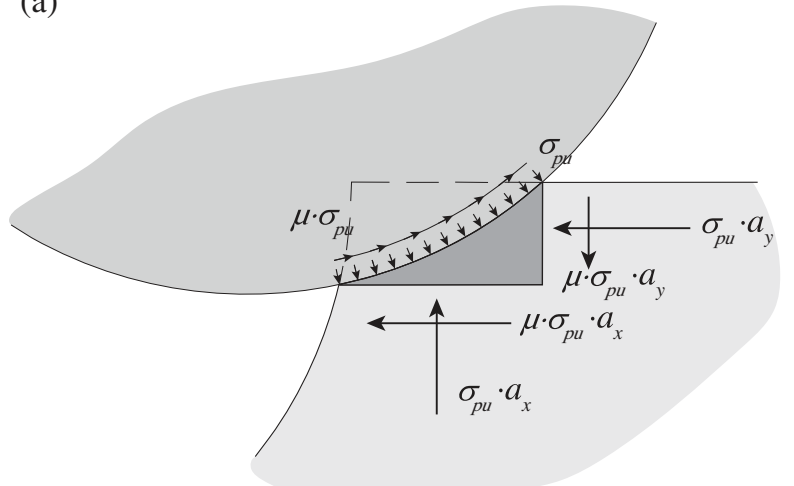

(b)

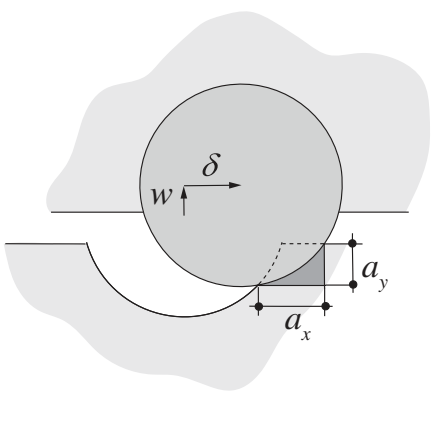

(c)

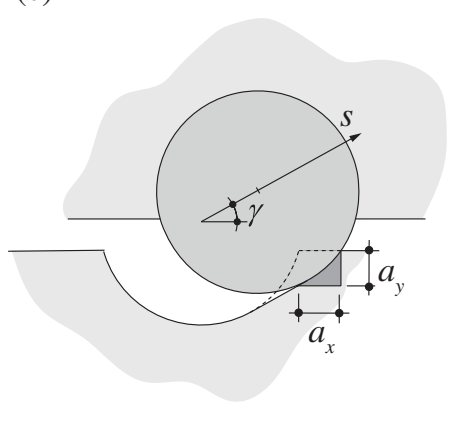

(d)

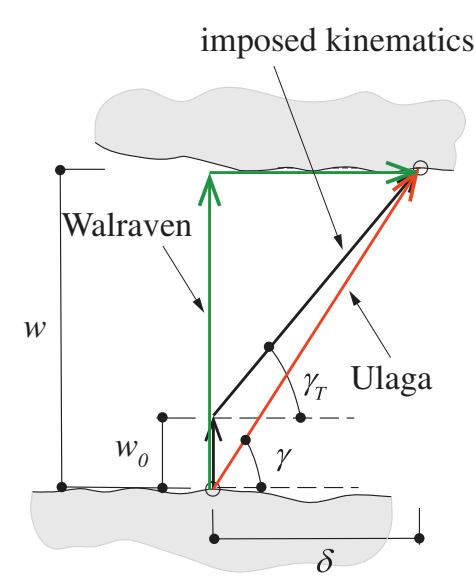

(e)

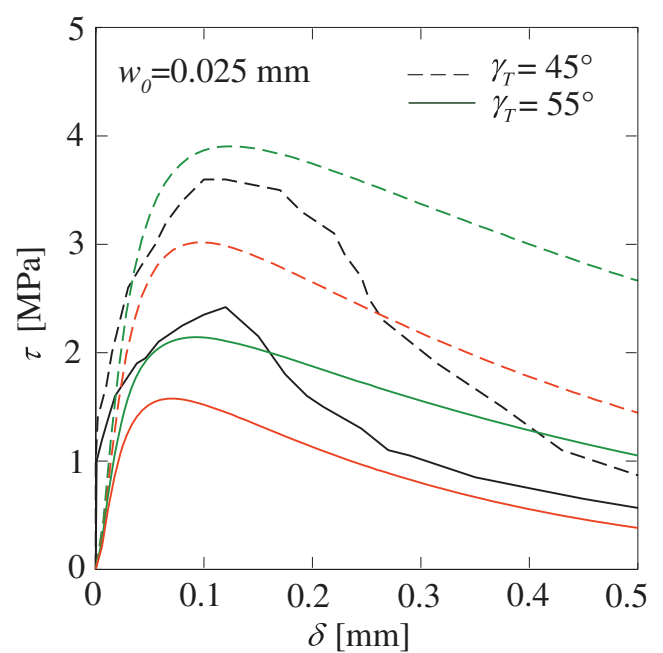

(f)

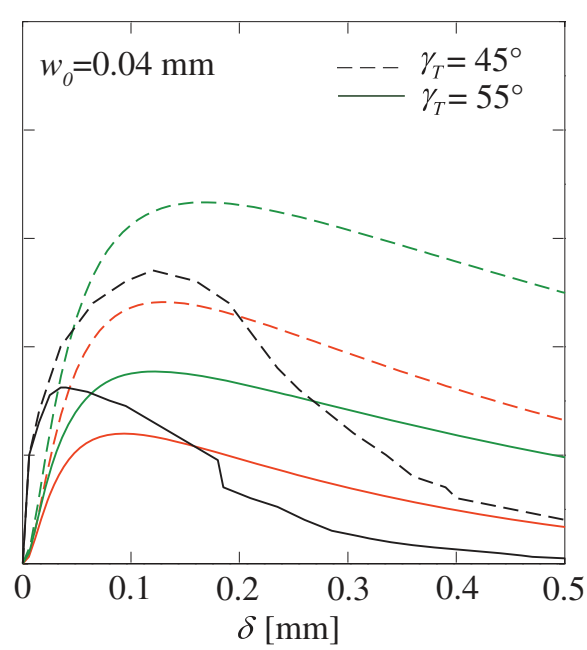

FIGURE 7 Aggregate interlock contribution: (a) contact zone between aggregate and cement matrix and aggregate interlock stresses; (b, c) projections areas according to the kinematics proposed by Walraven ${ }^{18}$ and Ulaga ${ }^{21}$; (d) crack kinematics proposed by Walraven and Ulaga and kinematics of mixedmode tests performed by Jacobsen et $\mathrm{al}^{22}$ (e-f) comparison of shear stresses experimentally measured by Jacobsen et $\mathrm{al}^{22}$ (black lines) and calculated according to the model of Walraven and the crack kinematics of Walraven ${ }^{18}$ (green lines) and Ulaga ${ }^{21}$ (red lines)

$V_{D, \text { tens }}=n \cdot E_{S} \cdot I \cdot \frac{d^{3} v(x)}{d x^{3}}=\frac{6 \cdot n \cdot E_{S} \cdot I}{l_{d a}{ }^{3}} \cdot\left[v_{0}-v_{1}+\frac{l_{d a}}{2}\left(v_{0}{ }^{\prime}+v_{1}{ }^{\prime}\right)\right]$,

where $n$ is the number of bars and $I$ is the moment of inertia of a longitudinal bar. It can be noted that if the reinforcement partially yields (SC58, SC63, and SC67a), the dowelling capacity of the rebars is reduced. ${ }^{27}$ For the only specimens where this situation happened, the contribution of dowelling to the overall shear strength was null or very limited and this phenomenon is thus neglected.

With respect to the dowelling action of the compression reinforcement $\left(V_{D \text {,compr }}\right)$, it can be activated only when the critical crack intercepts the compression reinforcement (SC59, SC60, and SC66). In these cases, the correspondent shear force contribution can be calculated from Equation (5).

\subsection{Compression chord and arching action}

The contribution of the inclined compression chord and the arching action ( $V_{C}$ in Figure 6) is calculated in the section located at the tip of the investigated critical shear crack (vertical section between the tip of the crack and the extreme compression fiber of the specimen, refer to the height $h_{F}$ in Figure 6). This is performed on the basis of the measured principal strains along this length and adopting the constitutive law for concrete explained below. When the critical shear crack propagates up to the region below the intermediate support (e.g., specimens SC58, SC63, SC60, and SC67), the investigated section corresponds to the one at the edge of the reaction plate consistently with the rest of the analyses (refer to Figure 2).

In this work, the strains have been computed from the DIC measurements in a number of points located at an average vertical distance of $6 \mathrm{~mm}$ in the portion investigated. For specimens SC52, SC54, and SC57, the DIC technique could not be used (readings at the investigated section were not available), but LED (light-emitting diode) targets were used, ${ }^{13}$ allowing also refined measurements of the principal strains in the compression zone. The principal strains could not be computed for specimens SC53 and SC55, due to the lack of any instrumentation in the critical region of the compression zone.

In this paper, the principal stress directions are assumed to be parallel to the principal strain directions and the 
principal stresses are directly computed from the principal strains. To that purpose, principal tensile stresses are calculated assuming a linear-elastic behavior of concrete before reaching its tensile strength $\left(\sigma_{1}=E_{c} \cdot \varepsilon_{1}\right.$ and $\sigma_{1}=0$ (if $E_{c} \cdot \varepsilon_{1}>f_{c t}$ ) refer to Figure 9, where $E_{c}$ is taken equal to $E_{c}=10,000 f_{c}^{1 / 3}$ in $\mathrm{MPa}$ ). Principal compressive stresses are computed according to a stress-strain relationship accounting for the pre- and post-peak behavior (refer to Figure 9a and Reference 28):

$$
\sigma_{2}=\frac{E c \cdot \varepsilon_{2}}{1+\left(\frac{\varepsilon_{2}}{\varepsilon_{0}}\right)^{\alpha}}
$$

with:

$$
\varepsilon_{0}=\frac{\alpha \cdot f_{c, \text { eff }}}{E_{c} \cdot(\alpha-1)^{\left(1-\frac{1}{\alpha}\right)}}
$$

and:

$$
\alpha=0.5+\frac{f_{c, e f f}}{20}+\frac{f_{c, e f f}^{2}}{1500}
$$

where $\varepsilon_{2}$ refers to the measured principal compressive strain and $f_{c, \text { eff }}$ is the effective compressive strength expressed in

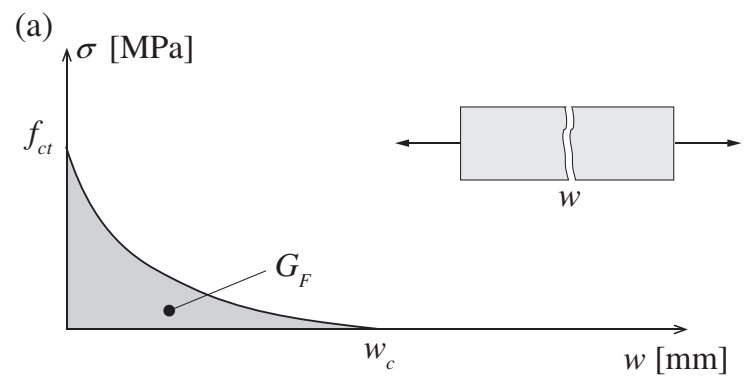

(b)

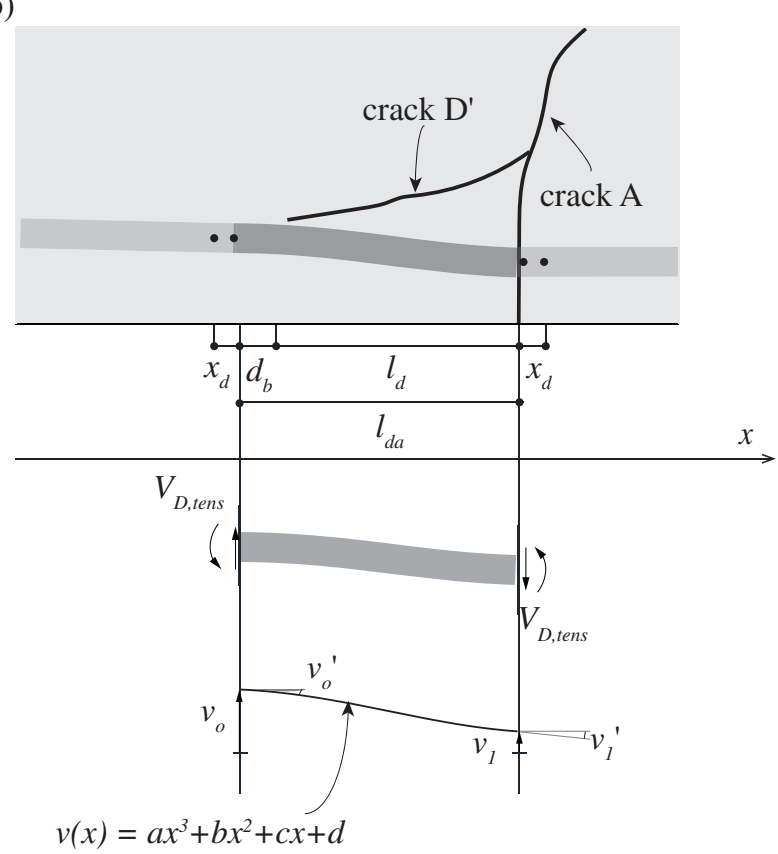

FIGURE 8 (a) Tension softening of concrete under pure tensile stresses; (b) dowelling action: deflection of the flexural reinforcement in the proximity of the dowelling crack (crack type $\mathrm{D}^{\prime}$ )

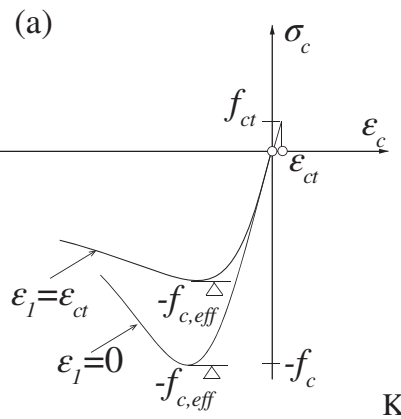

(b)

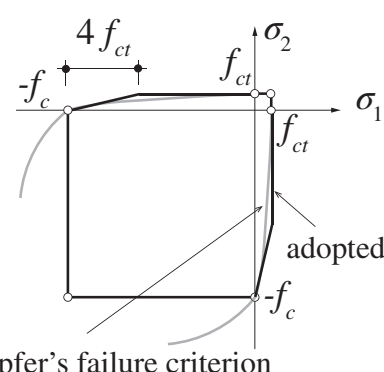

FIGURE 9 (a) Adopted stress-strain diagram for concrete ${ }^{28}$; (b) Kupfer's failure surface ${ }^{29}$ and the adopted one $\mathrm{e}^{30}$

MPa. It can be noted that according to the measured strains, the post-peak part of the curve was not governing for most specimens, and only limited post-peak deformations were attained in a few tests (e.g., specimens SC60, SC63, and SC67).

For uncracked concrete, $f_{c, \text { eff }}$ is derived on the basis of the biaxial failure criterion accounting for the interaction between tension and compression stresses. ${ }^{29}$ The concrete failure surface in the combined tension-compression regime (left upper and right lower quadrants) is simplified by a bilinear law (Figure 9b), whose slope is determined by that of the Mohr-Coulomb failure envelope, using a friction angle $\phi=37^{\circ} \cdot{ }^{30}$ Both the contribution of the inclined tension and compression stresses were accounted for in the calculation of the shear force $V_{C}$ with the pertinent surfaces and angles.

For specimens SC58, SC60, SC63, and SC67, however, smeared cracking (refer to Figure 2 and to cracks type $\mathrm{G}^{\prime \prime}$ in Figure $4 \mathrm{c}$ ) was observed within the compression zone (these cracks were not connected to the critical shear crack). For these cases (closer to the behavior of a cracked panel with smeared cracking), the tensile strength of concrete is neglected and the effective compressive strength is reduced on the basis of the compression-softening law proposed by Vecchio and Collins ${ }^{31}$ :

$$
f_{c, e f f}=f_{c} \cdot \frac{1}{0.8+170 \cdot \varepsilon_{1}} \leq f_{c}
$$

The shear stresses are then computed from the principal strains and principal stress directions. Finally, by integration of the shear stresses along the length $h_{F}$, the shear force $V_{C}$ is obtained.

\section{5 | Distributed load not carried by the critical shear crack}

In reinforced concrete members subjected to distributed load, a fraction of the load near the support is carried directly to the support without crossing the critical shear crack. ${ }^{15}$ The load directly strutted $V_{q}$ has been computed as the integration of the load applied between the intermediate support (right support) and the position at which the critical 
(a)

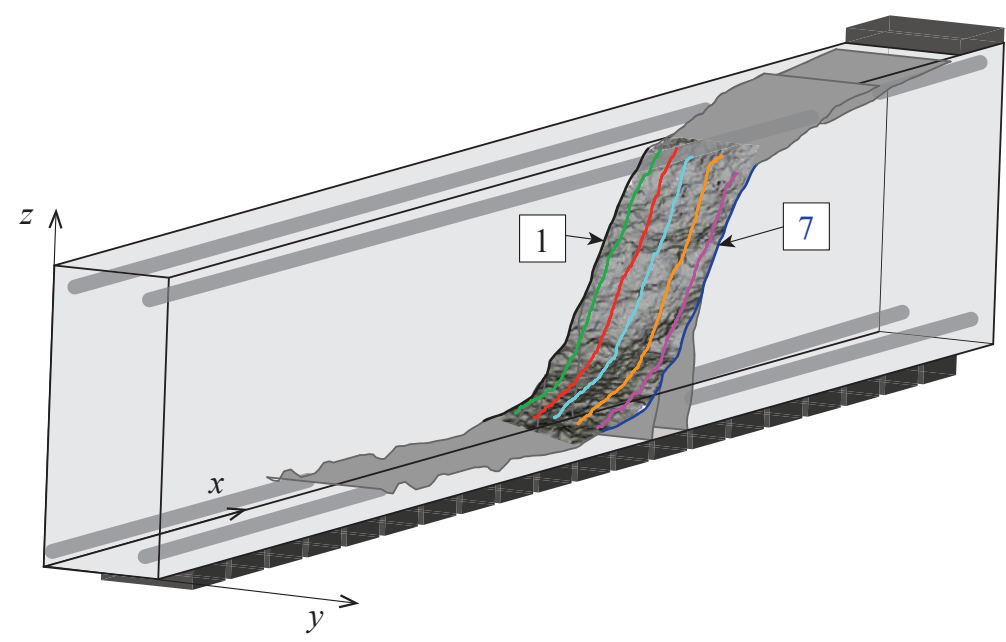

(b)

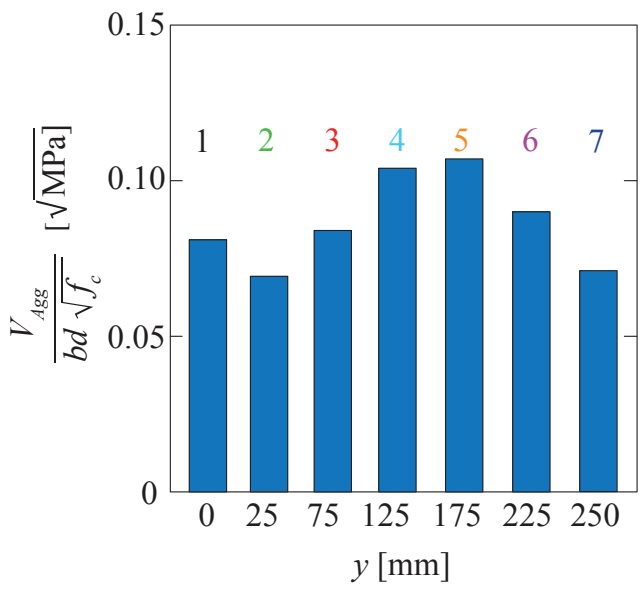

FIGURE 10 (a) Scan of the crack surface of specimen SC59 and geometry of the different sections through the width of the specimen used to calculate the aggregate interlock contribution; (b) aggregate interlock stresses computed at seven different sections (at different values of $y$ through the width of the specimen), accounting for the measured crack geometry. The crack kinematics is extrapolated from the measurements on the surface $(y=0$ mm)

shear crack (crack type A) intercepts the flexural reinforcement (e.g., specimen SC62, Figure 2). When a secondary flexural crack (crack type C) becomes connected during loading with a primary flexural crack and the crack propagation remains stable (e.g., specimen SC59, Figure 2), the interception between the secondary flexural crack and the longitudinal reinforcement is considered.

\section{6 | Calculated shear-transfer actions on the basis of the measured kinematics}

The main analysis of the contribution of the various sheartransfer actions is plotted in Figure 11, which depicts the amount of shear carried by each action for each specimen at the maximum load (tests SC51a, SC51b, SC52a, SC52b, SC55a, SC56, and SC67a are not considered due to lack of reliable measurements of the crack kinematics at peak load) .

The comparison between the sum of the estimated contributions and the acting shear force at the right support shows a good agreement (average ratio experimental-to-sum of estimated contributions equal to 1.01 with a coefficient of variation of $9 \%$ for 16 specimens in Figure 11, disregarding specimens SC53 and SC55 due to lack of detailed measurements of the principal strains in the compression zone).

The analyses have been performed on the basis of the DIC measurements obtained at one side of the specimen. It shall nevertheless be noted that the profile of the crack is not uniform through the width of the member (Figure 10a). This leads potentially to differences in the calculated contributions of the shear-transfer actions. As an instance, Figure 10b depicts the calculated shear force transferred by aggregate interlocking for seven crack profiles through the width of the member, where the crack displacements have been extrapolated from the measurements on the surface (average normalized aggregate interlock shear $V_{\text {Agg. }} / b d \sqrt{f_{c}}$ equal to 0.081 and COV 17\%). Although some level of variability exists due to the considered profile, it remains nevertheless within the scatter of the fundamental constitutive laws adopted. ${ }^{13,17}$

It can be noted that, at the maximum load, the amount of shear carried by each shear-transfer actions is variable. For specimens SC52, SC58, SC63, SC60, and SC67, the shear strength was governed (particularly for specimens SC58, SC63, and SC67) by the arching action, whereas for all the other specimens, the amount of shear carried by aggregate interlock is generally governing and the measured maximum shear force can be almost fully explained by the calculated contribution of the beam shear-transfer actions (aggregate interlock, dowelling action, residual tensile strength of concrete, and inclined compression chord) and the distributed load directly strutted. It is notable that for specimens SC59, SC60, and SC66, the critical shear cracks reached the compression reinforcement and activated the dowelling action of the compression reinforcement before failure.

In the following, the differences between cases governed by the arching action and by beam shear-transfer actions will be presented and discussed on the basis of some selected specimens.

\section{7 | Behavior of specimens governed by arching action}

Whenever a direct strut can develop (CCDT1, Figure 5a), the contribution of the inclined compression strut can be observed to be governing. This was for instance the case of specimen SC58, where the contribution of the beam shear-carrying actions only explains a limited amount of the total shear force (Figure 12a). For this specimen, in fact, the shear crack originated near the intermediate support region. It developed in a stable manner and almost did not penetrate within the 


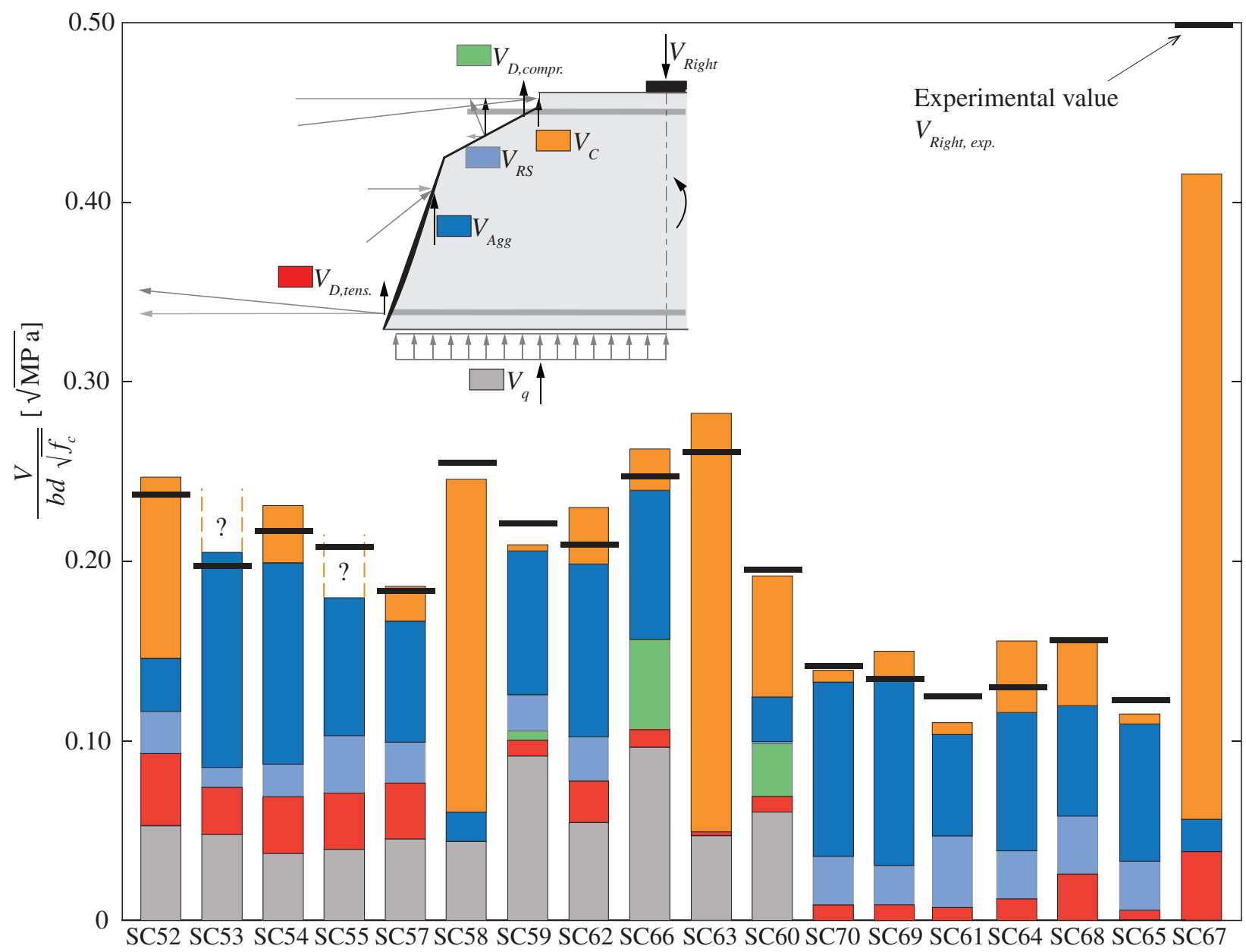

FIGURE 11 Amount of calculated shear carried by each shear-transfer action at peak load compared to the experimental shear strength $V_{\text {Right, }}$ exp

theoretical compression strut. After full development of the critical crack, at about $70 \%$ of the maximum load, even if the beam shear-transfer actions decayed (Figure 12a), the load could still be increased, as the arching action became dominant. Eventually, the flexural strength of the member was reached. A close look to the inclination of the principal compressive strains at the maximum load (Figure 12b) shows that the contribution of the direct strut was clearly governing.

A similar case was observed also for specimen SC67 (Figure 12c), where most of the shear force was transferred to the support through a direct compression strut. Failure of specimen SC67a occurred due to crushing of the compression zone, with the appearance of a crack (crack type $\mathrm{G}^{\prime \prime}$, Figure 4c) that was originated not from the flexural crack but from the intermediate support (right support) and that developed at a flat angle (first crack from the top side of the specimen, in Figure 2).

The arching action plays a role also for specimen SC60 (refer to Figure 11), even if the critical crack penetrated within the theoretical compression strut (Figure 12d). In fact, a close look to the cracking patterns and to the detailed measurements of the inclination of the principal compressive strains at the maximum load (Figure 12d) shows that a direct strut developed above the critical shear crack, which propagated in a stable manner up to the support.

\subsection{Behavior of specimens governed by beam shear- transfer actions}

When the critical crack does not develop close to the intermediate support, the contribution of the compression zone after the propagation of a crack type $\mathrm{F}$ from the primary flexural crack is rather limited. Representative cases are specimens SC51, SC53, SC54, SC55, SC56, SC57, SC59, SC62, SC70, SC69, SC61, SC64, SC68, and SC65 (refer to Figure 11). These tests correspond mostly to slender members.

In Figure 13a, the contribution of the different sheartransfer actions during loading is shown for specimen SC70. It can be observed that, before the development of the quasi-horizontal branch that initiated at about $40 \%$ of the maximum load, shear was carried by the compression chord, by aggregate interlock stresses, which are activated locally in the steeper parts of the crack, and by the residual tensile strength of concrete. After the propagation of the crack type $\mathrm{F}$, the contribution of aggregate interlock became dominant, whereas the contribution of the compression chord progressively decreased. At maximum load, the contribution of the compression chord is almost negligible (the direction of the principal compressive strains is practically horizontal, refer to Figure 13b) and the contribution of aggregate interlock is governing. 
(a)

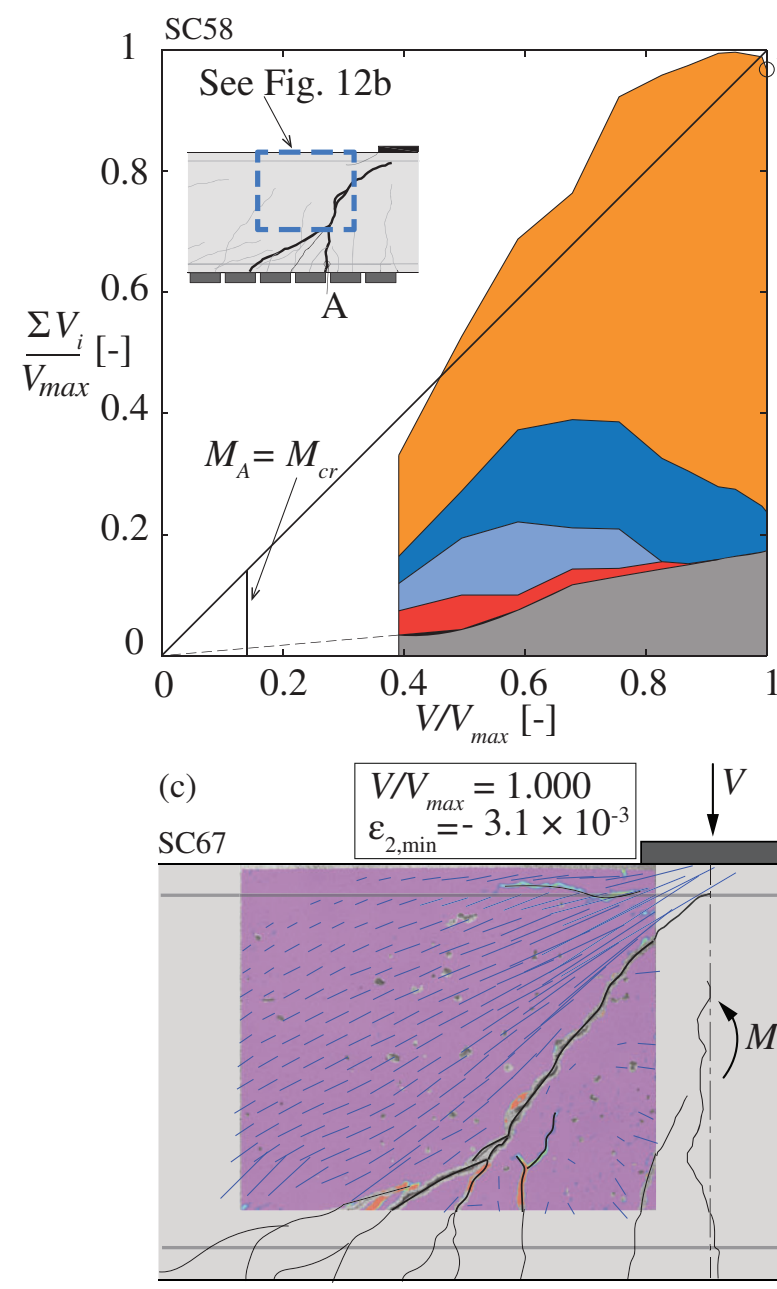

(b)
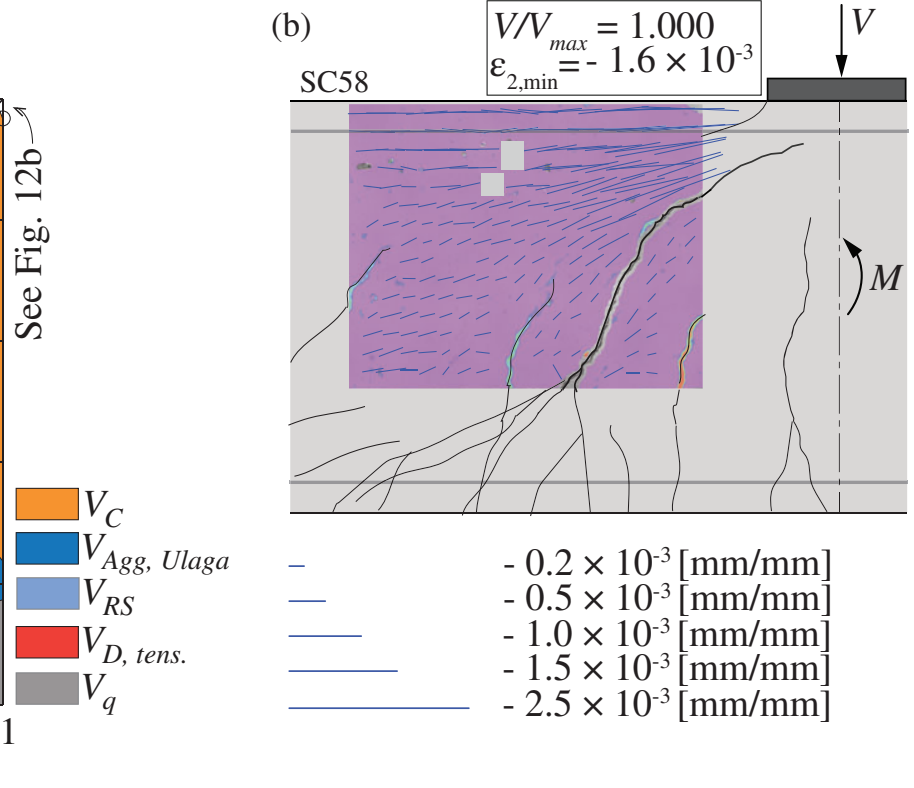

(d)

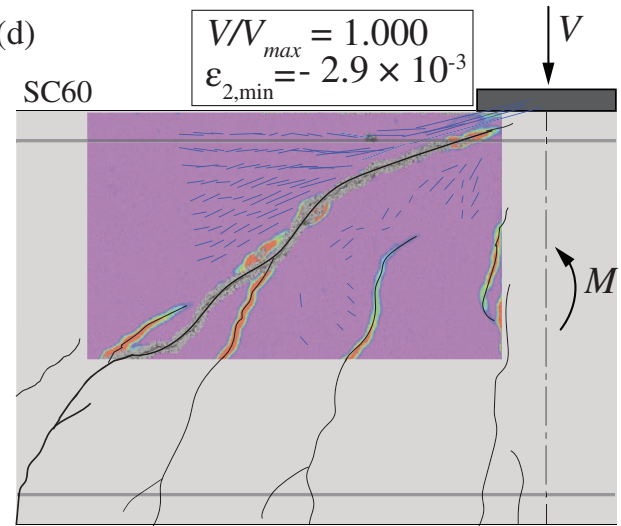

FIGURE 12 (a) Shear-transfer actions for specimen SC58. Direction and magnitude of the experimentally measured principal compressive strains at $V / V_{\max }=1.000$ for specimens: (b) SC58, (c) SC67, and (d) SC60

Figure 13c-e shows the normal and shear stresses and the forces computed along the crack surface on the basis the measured crack kinematics. With respect to the interface tangential stress $\tau$ (Figure 13c), it can be observed that it reaches a maximum value of $3.1 \mathrm{MPa}$ in the steeper part of the crack and it decreases for larger openings toward the tensile longitudinal reinforcement. The shear stresses become eventually null in the quasi-horizontal branch of the crack. From Figure 13e, it can be observed that aggregate interlock forces developed in the steeper parts of the critical crack, whereas the forces due to residual tensile strength of concrete developed in the quasihorizontal part of the critical crack (crack type F). It can thus be noted that both tension and compression normal forces can be developed at the critical shear crack (as observed in References 22, 32).

It is notable that for this specimen, another potential critical crack developed near the intermediate support. However, as the tip of the crack was located only at about $0.2 d$ from the intermediate support, the compression zone was able to carry a fraction of the shear force (inclined compressive strains above the tip of this crack in Figure 13b) and this crack did not become critical.

\section{5 | DISCUSSION OF RESULTS}

On the basis of the previous findings, it can be stated that the amount of shear force carried by the various shear-transfer actions during loading and at the maximum load depends on the location, geometry, and kinematics of the critical shear crack. Interesting results can be obtained by analyzing the contributions of the various shear-carrying mechanisms in a cross section located at representative cracks:

- The cantilever action, where the shear force at the cross section corresponding to a flexural crack is carried by the inclination of the compression chord, plays a significant role before the propagation of the critical crack in a quasi-horizontal manner (crack type F). This has been 
(a)

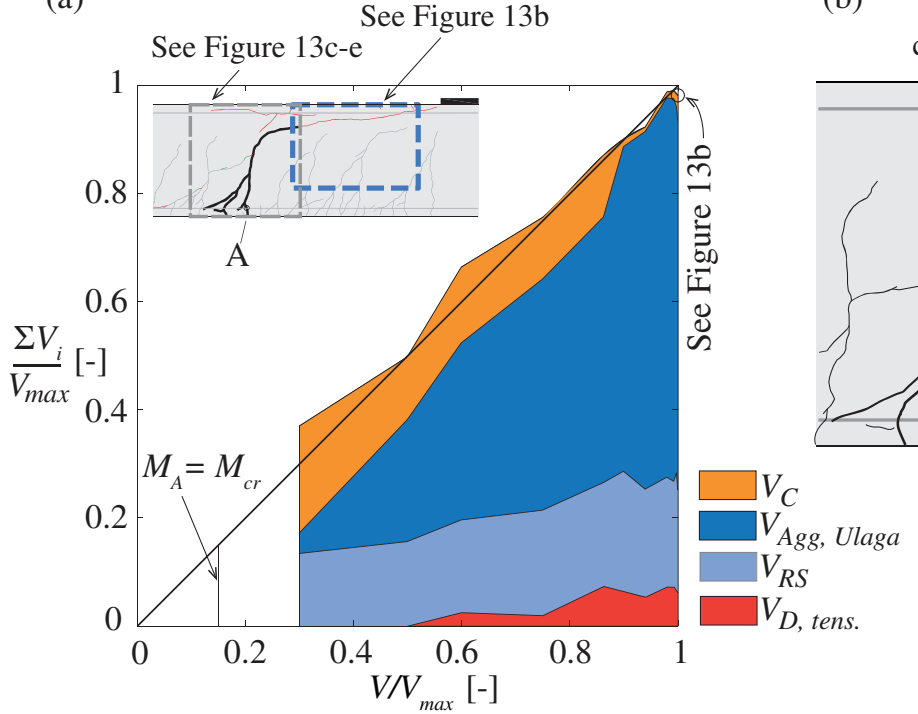

(c)

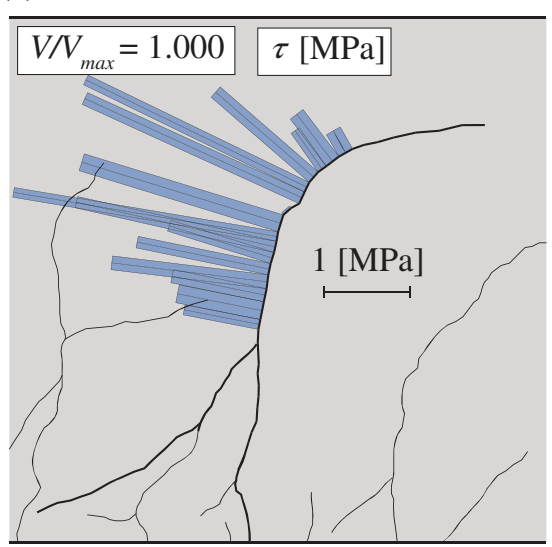

(d)

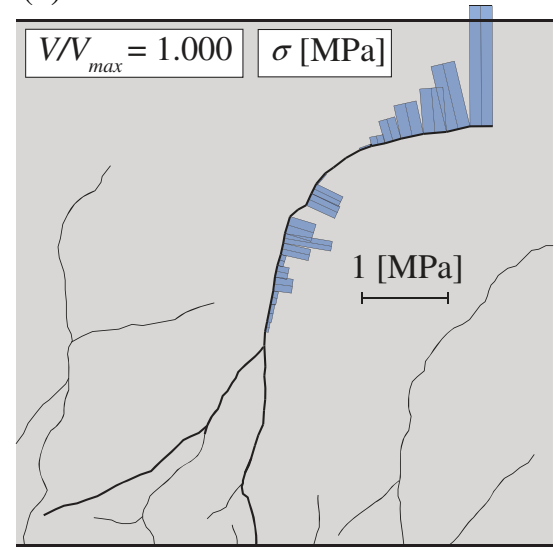

(b)

critical shear crack $V / V_{\text {max }}$
$\varepsilon_{2, \text { min }}=1.000$
$=$
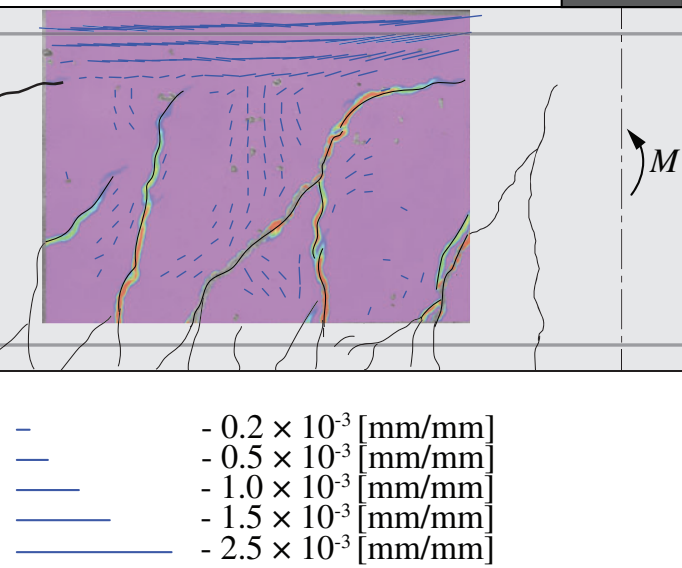

(e)

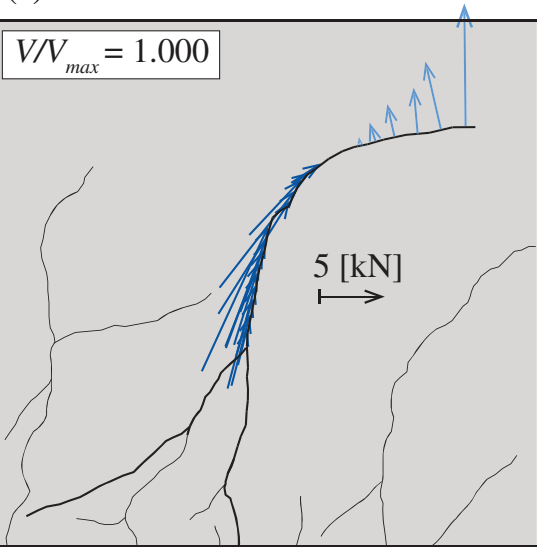

FIGURE 13 (a) Shear-transfer actions for specimen SC70; (b) direction and magnitude of the experimentally measured principal compressive strains at $V / V_{\max }=1.000$; (c) shear and (d) normal stresses developing along the crack surfaces, and (e) aggregate interlock and residual tensile forces at $V / V_{\max }=1.000$

observed to develop at a load level which may be significantly lower than the maximum load. ${ }^{13}$

- For slender members, characterized by a critical shear crack developing far from the intermediate support region, the contribution of the inclined compression chord at the maximum load is rather limited (less than $30 \%$ ), and, in some cases, almost negligible.

- The contribution of the arching action can be observed to be dominant only if the critical crack propagates near the intermediate support region and develops in a stable manner below the intermediate support plate (e.g., specimens SC52, SC58, SC63, SC60, SC67).

- The contribution of aggregate interlock depends on the geometry, location, and kinematics of the critical crack. Aggregate interlock stresses are mobilized when both opening and sliding develop and are activated in particular in the steeper and upper parts of the crack. For cracks developing below or in the vicinity of the intermediate support, hardly any aggregate interlock develops, since almost no crack sliding occurs (e.g., specimen SC52 in Reference 13). On the contrary, if the critical crack is sufficiently far from the intermediate support, aggregate interlock contributes for a significant percentage to the shear resistance (up to $80 \%$ of the total applied load).

- Residual tensile strength of concrete at the maximum load depends mainly on the opening and on the length and inclination of the quasi-horizontal branch of the critical crack (crack type F). The contribution of the residual tensile strength (up to $32 \%$ of the total applied shear force) is of particular relevance for cracks type $F$ with an extended length and a very limited crack opening (e.g., specimens SC61, SC68).

- The capacity of the dowelling action of the tensile reinforcement to transfer shear for specimens under a single point load depends mainly on the location of the critical crack and is very limited when the crack develops far from the end support (e.g., specimen SC70, Figure 13a), whereas it is more notable (up to $20 \%$ of the applied shear force) if the critical crack is located close to it (e.g., specimen SC68). In the case of continuous beams or cantilevers subjected to distributed loading, the contribution of the 
longitudinal reinforcement is generally more significant (see specimens SC52-SC55, SC57 in Figure 11).

- When the critical crack develops in a stable manner through the compression reinforcement, dowelling action of the compression reinforcement can develop and it can become efficient when the critical crack intercepts the reinforcement in the proximity of the intermediate support region. The compression reinforcement has been observed to contribute significantly in the post-peak shear strength (e.g., specimens SC64, SC68). In these cases, the compression reinforcement acts in a similar manner as the integrity reinforcement in slabs after punching in the column region. ${ }^{33}$

- With respect to continuous beams and cantilevers subjected to distributed loading, the load applied between the intermediate support region and the critical shear crack is assumed to be carried directly to the support by direct struts. On the basis of the current experimental results, the distance at which the critical crack intercepts the longitudinal reinforcement varies between $d$ and $2.6 d$ (refer to Figure 2 and Reference 13), lower values than those reported in Reference 15.

\section{6 | CONCLUSIONS}

In this paper, the results of seven reinforced concrete beams without shear reinforcement that complete an extensive experimental campaign with detailed measurements of 13 beams described by Cavagnis et al, ${ }^{13}$ are presented. In addition, the role of the shear-transfer actions and the mechanisms of shear failure are investigated in detail. The main conclusions are listed below:

1. The relative significance of the various potential sheartransfer actions varies with the cracking shape and position. During the process of loading, as cracks progress, some shear-transfer actions become predominant while others reduce their significance.

2. On the basis of refined kinematical measurements and by using suitable mechanical models, the contribution of each shear-transfer actions can be calculated:

- For slender specimens, the shear force is carried by a combination of aggregate interlock, dowelling action, residual tensile strength of concrete and inclined compression chord, with aggregate interlock being the dominant shear-transfer action.

- The arching action becomes the governing sheartransfer action only when the critical shear crack develops below the intermediate support and below the theoretical direct strut carrying shear. This is mostly the case of squat members.

3. These findings are confirmed by a close look to the principal compressive strains, which are almost horizontal when the contribution of the compression zone is rather limited, or almost negligible, while they are clearly inclined when a direct strut develops.

4. When the critical shear crack develops below the intermediate support and is approximately straight, aggregate interlocking is practically negligible.

5. Although a crack presents a variation on its geometry through the width of the member, analyses of the sum of the contributions of the shear-transfer actions do not reflect high sensitivity to this issue.

\section{ACKNOWLEDGMENT}

The authors gratefully acknowledge the support and funding from the Swiss Federal Road Authority, through the project AGB-2011-015.

\section{NOTATION}

a shear span (defined for specimens subjected to concentrated loads as the distance between the axis of the load and the axis of the right support)

$a_{x}, a_{y} \quad$ projected contact areas in $x$ and $y$ directions

$b \quad$ width of the beam

$c_{1}, c_{2} \quad$ constants

$d \quad$ effective flexural depth

$d_{b} \quad$ diameter of reinforcing bar

$d_{g} \quad$ maximum aggregate size

$f_{c} \quad$ concrete compressive strength measured in cylinder

$f_{c, \text { eff }} \quad$ effective compressive strength of concrete

$f_{c t} \quad$ concrete tensile strength

$h \quad$ beam height

$h_{F} \quad$ distance from the top compression fiber to the tip of crack type $\mathrm{F}$

span length

$l_{d}$

$l_{d a}$

$n$

$q$

$v_{0}, v_{1}$

$v_{0}{ }^{\prime}, v_{1}{ }^{\prime}$

length of the dowelling crack

length in which the longitudinal reinforcement is unbonded

number of longitudinal bars

distributed load

vertical displacement

normalized shear stress of members subjected to distributed loading

$v_{\text {point }} \quad$ normalized shear stress of members subjected to point loading

w $\quad$ crack width

$w_{0} \quad$ initial opening

$w_{c} \quad$ maximum crack width allowing tensile stresses transfer in concrete

$x_{d} \quad$ distance between two points located at the external regions of the dowelling crack used to calculate the vertical displacements and rotations at the extremities

$A_{x}, A_{y} \quad$ sum of the projected contact areas in $x$ and $y$ directions 
CCDT critical crack development type

DIC digital image correlation

$E_{c} \quad$ modulus of elasticity of concrete

$E_{s} \quad$ modulus of elasticity of steel

$G_{F} \quad$ fracture energy

I moment of inertia

$M \quad$ bending moment

$M_{c r} \quad$ cracking bending moment

$M_{\text {right }}$ bending moment at the intermediate (right) support

$M_{A} \quad$ bending moment at point A

$Q \quad$ concentrated load

$V \quad$ acting shear force

$V_{\text {exp }} \quad$ experimentally measured shear force at failure

$V_{\text {flex }} \quad$ flexural strength

$V_{\text {left }} \quad$ shear force at the end (left) support

$V_{\max } \quad$ shear force at failure (maximum value)

$V_{\text {right }}$ shear force at the intermediate (right) support

$V_{\text {Agg }} \quad$ contribution of aggregate interlock to shear

resistance

$V_{C} \quad$ contribution of inclined compression chord or arching action to shear resistance

$V_{D} \quad$ contribution of dowelling action to shear resistance

$V_{D, t e n s} \quad$ contribution of dowelling action of the tensile reinforcement

$V_{D, \text { compr }}$ contribution of dowelling action of the compression reinforcement

$V_{R S} \quad$ contribution of residual tensile stresses to shear resistance

$V_{q} \quad$ fraction of the distributed load carried by direct struts

$\alpha \quad$ brittleness factor

$\gamma \quad$ secant mixed-mode angle

$\gamma_{T} \quad$ tangent mixed-mode angle

$\delta \quad$ relative crack sliding

$\varepsilon_{c t} \quad$ principal tensile strain leading to $\sigma_{l}$ equal to $f_{c t}$

$\varepsilon_{0} \quad$ reference strain in the compression stress-strain relationship

$\varepsilon_{1} \quad$ principal tensile strains

$\varepsilon_{2} \quad$ principal compressive strains

$\varepsilon_{2, \min } \quad$ minimum measured principal compressive strains at peak load

$\mu \quad$ coefficient of friction

$\rho \quad$ reinforcement ratio of tension reinforcement

$\sigma \quad$ normal stresses

$\sigma_{1} \quad$ principal tensile stresses

$\sigma_{2} \quad$ principal compressive stresses

$\sigma_{p u} \quad$ compressive plastic strength of cement matrix

$\sigma_{\text {res }} \quad$ residual tensile strength of concrete

$\tau \quad$ shear stresses

\section{ORCID}

Francesco Cavagnis (D) http://orcid.org/0000-0002-7678-8346

Miguel Fernández Ruiz (D) http://orcid.org/0000-0001-6720-8162

\section{REFERENCES}

1. Fenwick RC, Paulay T. Mechanisms of shear resistance of concrete beams. J Struct Div ASCE. 1968;94(10):2325-2350.

2. ACI-ASCE Committee 445. Recent approaches to shear design of structural concrete. J Struct Eng. 1998;124(12):1375-1417.

3. Muttoni A, Fernández Ruiz M. Shear strength of members without transverse reinforcement as function of critical shear crack width. ACI Struct J. 2008;105(2):163-172.

4. Kani GNJ. The riddle of shear failure and its solution. ACI J. 1964;61(4):441-467.

5. Zararis PD. Shear strength and minimum shear reinforcement of reinforced concrete slender beams. ACI Struct J. 2003;100(2):203-214.

6. Tureyen AK, Frosch RJ. Concrete shear strength: another perspective. ACI Struct J. 2003;100(5):609-615.

7. Choi K-K, Kim J-C, Park H-G. Shear strength model of concrete beams based on compression zone failure mechanism. ACI Struct J. 2016;113(5):1095-1106.

8. Collins MP, Mitchell D, Adebar P, Vecchio F. A general shear design method. ACI Struct J. 1996;93(5):36-45.

9. Fernández Ruiz M, Muttoni A, Sagaseta J. Shear strength of concrete members without transverse reinforcement: A mechanical approach to consistently account for size and strain effects. Eng Struct. 2015;99:360-372.

10. Yang Y, Walraven J, den Uijl J. Shear behavior of reinforced concrete beams without transverse reinforcement based on critical shear displacement. J Struct Eng. 2016;143(1):4016146.

11. Tung ND, Tue NV. A new approach to shear design of slender reinforced concrete members without transverse reinforcement. Eng Struct. 2016;107:180-194.

12. Fisker J, Hagsten LG. Mechanical model for the shear capacity of R/C beams without stirrups:a proposal based on limit analysis. Eng Struct. 2016;115:220-231.

13. Cavagnis F, Fernández Ruiz M, Muttoni A. Shear failures in reinforced concrete members without transverse reinforcement: An analysis of the critical shear crack development on the basis of test results. Eng Struct. 2015;103:157-173.

14. Correlated Solutions. VIC 3D Software, Reference Manual. 2010. http:// www.correlatedsolutions.com

15. Pérez Caldentey A, Padilla P, Muttoni A, Fernández Ruiz M. Effect of load distribution and variable depth on shear resistance of slender beams without stirrups. ACI Struct J. 2012;109(5):595-603.

16. Campana S, Anastasi A, Fernández Ruiz M, Muttoni A. Analysis of sheartransfer actions on one-way RC members based on measured cracking pattern and failure kinematics. Mag Concr Res. 2013;65(6):386-404.

17. Huber $P$, Huber $T$, Kollegger J. Investigation of the shear behavior of RC beams on the basis of measured crack kinematics. Eng Struct. 2016;113:41-58.

18. Walraven JC. Fundamental analysis of aggregate interlock. J Struct Div. 1981;107(11):2245-2270.

19. Gambarova PG, Karakoc C. A new approach to the analysis of the confinement role in regularly cracked concrete elements. In: Transactions of the 7th International Conference on Structural Mechanics in Reactor Technology. 1983;H 5/7:251-261.

20. Li B, Maekawa K, Okamura H. Contact density model for stress transfer across cracks in concrete. J Fac Eng Univ Tokyo. 1989;40(1):9-52.

21. Ulaga T. Betonbauteile mit Stab- und Lamellenbewehrung: Verbund- und Zuggliedmodellierung [PhD thesis]. Thesis no. 15062 [in German]. Zurich, Switzerland: ETHZ; 2003:160.

22. Jacobsen JS, Poulsen PN, Olesen JF. Characterization of mixed mode crack opening in concrete. Mater Struct. 2012;45((1-2), 122):107.

23. Guidotti R. Poinçonnement des planchers-dalles avec colonnes superposées fortement sollicitées [PhD thesis]. Thesis no. 4812 [in French]. Leausanne, Switzerland: Ecole Polytechnique Fédérale de Lausanne; 2010:416.

24. Hillerborg A, Modéer M, Petersson PE. Analysis of crack formation and crack growth in concrete by means of fracture mechanics and finite elements. Cem Concr Res. 1976;6(6):773-781.

25. Hordijk DA. Tensile and tensile fatigue behaviour of concrete; experiments, modelling and analysis. Heron. 1992;37(1):3-79.

26. Fédération Internationale du Béton (fib). fib Model Code for Concrete Structures 2010. Ernst \& Sohn, Germany; 2013:434. 
27. Hars E, Niketić F, Fernández Ruiz M. Response of RC panels accounting for crack development and its interaction with rebars. Mag Concr Res. 2017; https://doi.org/10.1680/jmacr.17.00077.

28. Fernández Ruiz M, Muttoni A, Gambarova PG. Relationship between nonlinear creep and cracking of concrete under uniaxial compression. $J A d v$ Concr Techno. 2007;5(3):383-393.

29. Kupfer H, Hilsdorf HK, Rusch $\mathrm{H}$. Behavior of concrete under biaxial stresses. ACI J Proc. 1969;66(8):656-666.

30. Nielsen MP, Hoang LC. Limit Analysis and Concrete Plasticity. CRC Press, Taylor \& Francis Group: Boca Raton, Florida, US; 2016.

31. Vecchio FJ, Collins MP. The modified compression field theory for reinforced concrete elements subjected to shear. ACI J. 1986;83(2):219-231.

32. Calvi PM, Bentz EC, Collins MP. Reversed cyclic experiments on shear stress transfer across cracks in reinforced concrete elements. ACI Struct J. 2016;113(4):851-859.

33. Fernández Ruiz M, Mirzaei Y, Muttoni A. Post-punching behavior of flat slabs. ACI Struct J. 2013;110(5):801-812.

\section{AUTHOR'S BIOGRAPHIES}

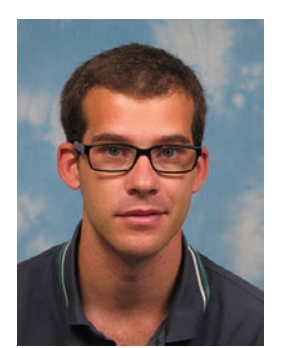

Francesco Cavagnis, PhD Candidate École Polytechnique Fédérale de Lausanne School of Architecture Civil and Environmental Engineering Station 18, CH-1015, Lausanne, Switzerland francesco.cavagnis@epfl.ch

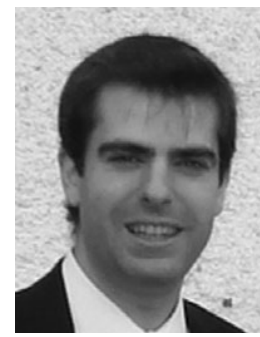

Miguel Fernández Ruiz, Senior Lecturer École Polytechnique Fédérale de Lausanne School of Architecture Civil and Environmental Engineering Station 18, CH-1015, Lausanne, Switzerland miguel.fernandezruiz@epfl.ch

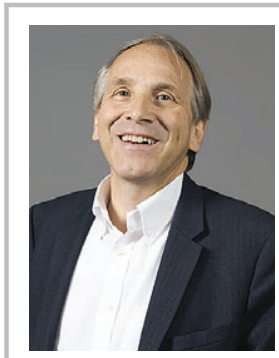

Aurelio Muttoni, Professor École Polytechnique Fédérale de Lausanne School of Architecture Civil and Environmental Engineering Station 18, CH-1015, Lausanne, Switzerland aurelio.muttoni@epfl.ch

How to cite this article: Cavagnis F, Fernández Ruiz M, Muttoni A. An analysis of the shear-transfer actions in reinforced concrete members without transverse reinforcement based on refined experimental measurements. Structural Concrete. 2017;1-16. https://doi.org/10.1002/suco.201700145 